\title{
Renal sympathetic denervation restores aortic distensibility in patients with resistant hypertension: data from a multi-center trial
}

\author{
Lukas Stoiber $^{1}$ (1) - Felix Mahfoudd ${ }^{2,3}$. Seyedeh Mahsa Zamani ${ }^{1} \cdot$ Tomas Lapinskas $^{1,8} \cdot$ Michael Böhm $^{2}$. \\ Sebastian Ewen ${ }^{2}$. Saarraaken Kulenthiran ${ }^{2}$. Markus P. Schlaich ${ }^{4,5} \cdot$ Murray D. Esler $^{5} \cdot$ Tommy Hammer $^{6}$. \\ Knut Haakon Stensæth ${ }^{6} \cdot$ Burkert Pieske $^{1,7,9} \cdot$ Stephan Dreysse $^{1} \cdot$ Eckart Fleck $^{1} \cdot$ Titus Kühne $^{9,10,11}$. \\ Marcus Kelm ${ }^{9,10,11} \cdot$ Philipp Stawowy ${ }^{1} \cdot$ Sebastian Kelle ${ }^{1,7,9}$
}

Received: 4 December 2017 / Accepted: 5 March 2018 / Published online: 8 March 2018

(c) The Author(s) 2018. This article is an open access publication

\begin{abstract}
Renal sympathetic denervation (RDN) is under investigation as a treatment option in patients with resistant hypertension (RH). Determinants of arterial compliance may, however, help to predict the BP response to therapy. Aortic distensibility (AD) is a well-established parameter of aortic stiffness and can reliably be obtained by CMR. This analysis sought to investigate the effects of RDN on AD and to assess the predictive value of pre-treatment $\mathrm{AD}$ for $\mathrm{BP}$ changes. We analyzed data of 65 patients with RH included in a multicenter trial. RDN was performed in all participants. A standardized CMR protocol was utilized at baseline and at 6-month follow-up. AD was determined as the change in cross-sectional aortic area per unit change in BP. Office BP decreased significantly from $173 / 92 \pm 24 / 16 \mathrm{mmHg}$ at baseline to $151 / 85 \pm 24 / 17 \mathrm{mmHg}(p<0.001)$ 6 months after RDN. Maximum aortic areas increased from $604.7 \pm 157.7$ to $621.1 \pm 157.3 \mathrm{~mm}^{2}(p=0.011)$. AD improved significantly by $33 \%$ from $1.52 \pm 0.82$ to $2.02 \pm 0.93 \times 10^{-3} \mathrm{mmHg}^{-1}(p<0.001)$. Increase of AD at follow-up was significantly more pronounced in younger patients $(p=0.005)$ and responders to $\operatorname{RDN}(p=0.002)$. Patients with high-baseline AD were significantly younger $(61.4 \pm 10.1$ vs. $67.1 \pm 8.4$ years, $p=0.022)$. However, there was no significant correlation of baseline $\mathrm{AD}$ to response to RDN. AD is improved after RDN across all age groups. Importantly, these improvements appear to be unrelated to observed BP changes, suggesting that RDN may have direct effects on the central vasculature.
\end{abstract}

Keywords Renal denervation - Aortic distensibility - Compliance - Vascular stiffness - Cardiovascular magnetic resonance · CMR $\cdot$ Resistant hypertension

Electronic supplementary material The online version of this article (https://doi.org/10.1007/s00392-018-1229-z) contains supplementary material, which is available to authorized users.

Lukas Stoiber

stoiber@dhzb.de

1 Department of Internal Medicine/Cardiology, German Heart Center Berlin, Augustenburger Platz 1, 13353 Berlin, Germany

2 Division of Cardiology, Angiology and Intensive Internal Medicine, Department of Internal Medicine III, Saarland University, Homburg, Germany

3 Institute for Medical Engineering and Science, Massachusetts Institute of Technology, Cambridge, MA, USA

4 Dobney Hypertension Centre, School of Medicine, University of Western Australia-Royal Perth Hospital Unit, Crawley, Australia

5 Baker Heart and Diabetes Institute, Melbourne, Australia

\section{Abbreviations \\ AD Aortic distensibility \\ ANOVA Analysis of variance}

6 Department of Radiology and Nuclear Medicine, St. Olavs Hospital and Institute of Circulation and Medical Imaging, Norwegian University of Science and Technology, Trondheim, Norway

7 Department of Internal Medicine/Cardiology, Charité Campus Virchow Klinikum, Berlin, Germany

8 Department of Cardiology, Medical Academy, Lithuanian University of Health Sciences, Kaunas, Lithuania

9 DZHK (German Center for Cardiovascular Research), Partner Site Berlin, Berlin, Germany

10 Department of Congenital Heart Disease and Pediatric Cardiology, German Heart Center Berlin, Berlin, Germany

11 Institute for Computational and Imaging Science in Cardiovascular Medicine, Charité Berlin, Berlin, Germany 


$\begin{array}{ll}\text { BP } & \text { Blood pressure } \\ \text { CMR } & \text { Cardiac magnetic resonance tomography } \\ \text { AD } & \text { Aortic distensibility } \\ \text { DBP } & \text { Diastolic blood pressure } \\ \text { ICC } & \text { Intra-class coefficient } \\ \text { ISH } & \text { Isolated systolic hypertension } \\ \text { LV } & \text { Left ventricle } \\ \text { LVEF } & \text { Left ventricular ejection fraction } \\ \text { LVH } & \text { Left ventricular hypertrophy } \\ \text { PP } & \text { Pulse pressure } \\ \text { PWV } & \text { Pulse wave velocity } \\ \text { RDN } & \text { Renal sympathetic denervation } \\ \text { RH } & \text { Resistant hypertension } \\ \text { RV } & \text { Right ventricle } \\ \text { SBP } & \text { Systolic blood pressure } \\ \text { SD } & \text { Standard deviation } \\ \text { SSFP } & \text { Steady-state free precession sequence }\end{array}$

\section{Introduction}

Arterial stiffness elevates systolic blood pressure (SBP) as it accelerates pressure waves returning to the heart [1]. Patients with resistant hypertension $(\mathrm{RH})$, defined as uncontrolled hypertension despite the concurrent use of at least three antihypertensive drugs including a diuretic, are at high risk for cardiovascular events [2, 3]. Aortic distensibility (AD) provides an estimation of the elastic response to the pulsatile blood flow and is regarded as one of the key parameters of aortic elasticity. AD measurements are worthwhile to detect even subclinical vascular changes resulting in response to aging and increased systolic pressure [4, 5]. While advanced age seems to be the major factor of the arterial remodeling process, decrease in $\mathrm{AD}$ is more pronounced before the fifth decade of life [1,5]. Cardiac magnetic resonance imaging (CMR) allows non-invasive imaging of the entire aorta and makes evaluation of $\mathrm{AD}$ accessible and accurate $[6,7]$.

Catheter-based renal denervation (RDN) has been suggested as a treatment option for $\mathrm{RH}$, aiming at modulating renal and central sympathetic activity as one of the factors contributing to elevated BP, and likely increased arterial stiffness and thus afterload. RDN has also been shown to reduce target organ damage, in particular left ventricular hypertrophy, an effect that seemed to be independent of its blood-pressure lowering capacity $[3,8,9]$.

However, the results of the latest randomized trials on RDN were mixed and considerable variability in the response to RDN was observed among patients [10-13]. The current study aimed to assess the effects of RDN on aortic structural and functional characteristics and to investigate whether pre-treatment $\mathrm{AD}$ can predict the $\mathrm{BP}$ response to RDN.

\section{Methods}

\section{Study population and design}

This present trial was planned as a prospective, multicenter trial and implemented at four investigational sites: two in Germany, one in Norway, and one in Australia. A total of 65 patients with RH undergoing RDN between May 2009 and January 2014 were prospectively enrolled. $\mathrm{RH}$ was defined as an office SBP above goal ( $\geq 140 \mathrm{mmHg}$ ) or mean ambulatory $24-\mathrm{h} \mathrm{SBP}>135 \mathrm{mmHg}$ despite the use of $\geq 3$ antihypertensive agents of different classes at maximum or highest tolerated doses, including a diuretic $[2,14]$. BP measurement methods are described in detail elsewhere [14-16]. Office BP was obtained at entry and 6 months after treatment. Office BP readings were taken during the MRI with an automatic brachial oscillometric Omron HEM-705 monitor (Omron Healthcare, Vernon Hills, IL) after at least 5 min of rest according to the Standard Joint National Committee VII Guidelines. Averages of the triplicate measures were calculated and AD was calculated from the averaged brachial PP. Patients with general contraindications for CMR were excluded as well as patients with contraindications for RDN [15]. A stable antihypertensive drug regimen was another inclusion criterion and changes in treatment during the study period were only permitted when medically required. A standardized CMR protocol was followed at both baseline and 6-month follow-up to assess myocardial function and volumes. BP was determined during both MR examinations to quantify AD. Clinical assessment, including history taking and physical examination, evaluation of vital signs, and review of medication compliance, was performed at both timepoints. A Symplicity Flex system catheter (Medtronic, Minneapolis, MN, USA) was used in the RDN procedures. The study was approved by the local institutional review board (Charité-Universitätsmedizin Berlin) in accordance with all the ethical standards and written informed consent was provided by all patients before inclusion. Measurements were performed as an extension to the protocols of the Symplicity trials (NCT00664638, NCT00888433, and NCT01888315). The results presented here are an extension to the work previously published, based on 55 patients of the same cohort [3].

\section{CMR protocol}

All studies were performed before and 6 months after RDN using a 1.5 T Achieva MRI scanner (Philips Healthcare, Best, The Netherlands) or 1.5 T Siemens Symphony or a $1.5 \mathrm{~T}$ Siemens Aera MRI system (Siemens Healthcare 
Sector, Erlangen, Germany). Cine images were acquired during breath holds of 10-15 s using vector electrocardiogram gating and steady-state free precession sequence (SSFP).

\section{CMR analysis}

\section{LV measurements}

CMR measurements were performed as previously reported and in accordance with the recommendations of the task force for post-processing of the Society for Cardiovascular MR [17, 18]. We used Qmass software version 8.1 (Medis Suite version 2.1., Medis, The Netherlands) for offline CMR analyses. Endocardial and epicardial borders were traced manually at end-diastole and end-systole, with exclusion of the papillary muscles from LVM to achieve better reproducibility [19]. LV volumes and mass were calculated using the summation of slices method [20]. LV measurements including wall thickness and internal dimensions were obtained using the SAX view basal to the tips of the papillary muscles [21].

\section{Aortic area measurements}

The inner diameter of the aortic wall was traced manually and contouring was then adapted with the contouring tool in Qmass software version 8.1 (Medis Suite version 2.1., Medis, The Netherlands). All measures were performed three times and then averaged. We used cross-sectional areas of the descending aorta obtained in the standard 4-chamber cine images at baseline and 6-month follow-up. For the evaluation of intra- and inter-observer variability, aortic area measurements were repeated by both the first observer and a second observer in ten patients.

To calculate $\mathrm{AD}$, we first determined aortic strain, defined as the relative change in area, and then normalized this value with the peripheral PP obtained at the time point of the CMR (average of three measures). This relation can, as previously published, be described as

Aortic distensibility $=\frac{A_{\max }-A_{\min }}{A_{\min } \times \text { pulse pressure }}$,

where $A_{\max }$ and $A_{\min }$ refer to the corresponding maximal and minimal cross-sectional areas of the descending aorta in our case $[5,22]$.

\section{Statistical analysis}

All data are presented as mean \pm standard deviation. Differences in mean values were compared using Student's $T$ test if data were normally distributed or the Wilcoxon test if normality could not be assumed. Kolmogorov-Smirnov test was used to assess distribution. Mann-Whitey- $U$ test was used to compare responders with non-responders. To compare the characteristics between different groups regarding AD, we used ANOVA and Kruskal-Wallis tests whenever variables were continuous and the Chi-square test or Fisher's exact test for categorical variables. To address the regression to the mean phenomenon and the confounding by indication issue, we used general linear models (GLM) for repeated measurements including covariates. We assessed the effect of RDN between certain groups as previously described using baseline SBP and DBP as covariates in the calculation [23]. Univariate correlations between parameters were obtained using Pearson's correlation coefficients. Intra- and inter-observer variability is displayed in Bland-Altman plots in our supplementary material. In addition, the intra-class correlation coefficient (ICC) was considered as excellent with a value of $>0.7$ [24]. A $p$ value $<0.05$ was considered statistically significant. All statistical analyses were performed using IBM SPSS Statistics for Windows (Version 24.0, SPSS Inc., Chicago, IL, USA).

\section{Reproducibility}

Bland-Altman plots and ICC analysis are provided in Supplemental Figure S2 and Supplemental Table S2 for intraobserver and inter-observer variability measurements for cross-sectional aortic area. The intra- and inter-observer concordances (95\% confidence interval) were 0.940 (0.886-0.968) and 0.993 (0.987-0.996), respectively, indicating excellent consistency of repeated evaluations.

\section{Results}

\section{Study population}

Sixty-five patients with RH were included in this analysis. Seven patients had to be excluded due to low image quality. RDN was performed successfully in all patients. No loss to follow-up was reported during the study period of 6 months. The baseline clinical characteristics of the patients included in the analysis are presented in Table 1.

\section{Blood pressure}

Office systolic and diastolic BP decreased significantly from $173 / 92 \pm 24 / 16 \mathrm{mmHg}$ at baseline to $151 / 85 \pm 24 / 17 \mathrm{mmHg}$ $(p<0.001) 6$ months after RDN. 
Table 1 Baseline characteristics of the study cohort

\begin{tabular}{ll}
\hline Parameter & All patients $(n=58)$ \\
\hline Baseline clinical characteristics of the study cohort \\
Age (years) & $64.4 \pm 9.6$ \\
Male & $42(72 \%)$ \\
BMI $\left(\mathrm{kg} \mathrm{m}^{-2}\right)$ & $29.3 \pm 4.2$ \\
Stroke & $8(14 \%)$ \\
Type 2 diabetes & $26(45 \%)$ \\
No. of antihypertensive drugs & $4.6 \pm 1.6$ \\
ACE inhibitors/ARBs & $51(88 \%)$ \\
$\beta$-Blockers & $49(84 \%)$ \\
Calcium channel blockers & $45(78 \%)$ \\
Diuretics & $46(79 \%)$ \\
Sympatholytics & $24(41 \%)$ \\
Direct renin inhibitors & $18(31 \%)$ \\
No. of patients with isolated SHT & $28(48 \%)$ \\
Baseline hemodynamics of the study cohort & \\
Systolic BP (mmHg) & $172.8 \pm 23.6$ \\
Diastolic BP (mmHg) & $92.3 \pm 16.1$ \\
Pulse pressure (mmHg) & $79.6 \pm 15.5$ \\
\hline
\end{tabular}

Data are expressed as mean and standard deviation

No. number, $B M I$ body mass index, SHT systolic hypertension, $B P$ blood pressure, $A C E$ angiotensin converting enzyme, $A R B$ angiotensin receptor blocker

\section{LV measurements}

Functional and anatomical parameters are depicted in Table 2. No significant changes between baseline and 6 months were observed for normalized LV end-diastolic volume (LVEDVI $85 \pm 22$ vs. $84 \pm 23 \mathrm{~mL} \mathrm{~m}^{-2} ; p=0.325$ ); however, normalized LV end-systolic volume (LVESVI $39 \pm 17$ vs. $\left.36 \pm 15 \mathrm{~mL} \mathrm{~m}^{-2} ; p=0.045\right)$ decreased significantly. There were no significant changes of LV internal dimensions at 6 months. Ejection fraction increased from $55.4 \pm 11$ to $57.5 \pm 9.3 \%, p=0.057$. $\mathrm{LV}$ mass indexed to BSA (LVMI) significantly decreased from $57.7 \pm 16.3$ to $54.4 \pm 15.4 \mathrm{~g} \mathrm{~m}^{-2}, p<0.001$.

\section{Arterial measurements}

Arterial measurements included data of minimal and maximal cross-sectional areas of the descending aorta and absolute changes in aortic areas as well as aortic strain. Data are available for all patients $(n=58)$ and are summarized in Table 2. Maximum aortic area increased significantly from $604.7 \pm 157.7 \mathrm{~mm}^{2}$ at baseline to $621.1 \pm 157.3 \mathrm{~mm}^{2}$ $(p=0.011) 6$ months after RDN. A non-significant trend was observed for an increase of minimal aortic area, absolute change in aortic area, and aortic strain between baseline and 6-month follow-up.

\section{Distensibility measurements}

Values of distensibility were based on the aortic strain and pulse pressure obtained. In general, AD increased significantly by $33 \%$ from $1.52 \pm 0.82 \times 10^{-3} \mathrm{mmHg}^{-1}$ at baseline to $2.02 \pm 0.93 \times 10^{-3} \mathrm{mmHg}^{-1}$ at follow-up $(p<0.001)$ (Fig. 1).

\section{Age-related changes in distensibility}

The baseline AD was age-dependent $(p=0.015)$ and the increase in $\mathrm{AD}$ was more pronounced in younger patients (Figs. 2, 3). Pearson's estimates showed a non-significant correlation between age and change in $\operatorname{AD}(p=0.087)$ (Table S1). To further evaluate the impact of age on AD, patients were separated into tertiles related to age at baseline (Table 3 ). The group with young age (35-60 years) showed the highest change in $\mathrm{AD}$, from $1.87 \pm 0.82 \times 10^{-3} \mathrm{mmHg}^{-1}$ at baseline to $2.62 \pm 1.10 \times 10^{-3} \mathrm{mmHg}^{-1}$ at follow-up $(p=0.005)$. Interestingly, AD increased as well in the moderate age subgroup (61-68 years), from $1.57 \pm 0.98$ to $1.98 \pm 0.72 \times 10^{-3} \mathrm{mmHg}^{-1}(p=0.064)$, and even in the highest age subgroup (69-81 years), from $1.14 \pm 0.45$ to $1.48 \pm 0.56 \times 10^{-3} \mathrm{mmHg}^{-1}(p=0.044)$, indicating that RDN improved arterial stiffness also in the elderly study population (Fig. 4). Baseline adjusted changes in AD between these three groups differed significantly $(p=0.008)$.

\section{Distensibility and response to RDN}

In total, 37/58 (64\%) patients after RDN showed an SBP reduction of at least $10 \mathrm{mmHg}$ and were subsequently defined as "responders" [25]. Differences in results between responders and non-responders are summarized in Table 4. Absolute $A D$ values after $R D N$ increased in all patients regardless of the treatment response. AD increased from $1.51 \pm 0.8$ to $2.0 \pm 0.84 \times 10^{-3} \mathrm{mmHg}^{-1}(p=0.002)$ in responders and from $1.54 \pm 0.93$ to $1.99 \pm 1.11 \times 10^{-3} \mathrm{mmHg}^{-1}$ $(p=0.046)$ in non-responders (Figure $\mathrm{S} 1)$. Interestingly, in 18/21 (86\%) non-responders, maximum aortic areas significantly increased from $648.2 \pm 192.6$ to $675.4 \pm 201.7 \mathrm{~mm}^{2}$ $(p=0.005)$, whereas this change was less pronounced in responders, with 20/37 (54\%) increasing from $580.0 \pm 130.7$ to $590.3 \pm 117.7 \mathrm{~mm}^{2}(p=0.294)$.

\section{Distensibility amount groups}

Based on the median $\mathrm{AD}$ at baseline, patients were divided into two groups. An absolute AD value of $\geq 1.4747 \times 10^{-3} \mathrm{mmHg}^{-1}$ was considered high-baseline AD. Comparison of baseline characteristics with respect to $\mathrm{AD}$ is summarized in Table 5. High-baseline AD patients were significantly younger than the low-baseline 
Table 2 Patients' anatomic, hemodynamic, and arterial measures at baseline and follow-up

\begin{tabular}{lllr}
\hline Parameter & Baseline & 6 -month follow-up & $p$ value \\
\hline Anatomic and functional analysis $(n=50$ patients) & & & \\
LVEDVI $\left(\mathrm{mL} \mathrm{m}^{-2}\right)$ & $85.0 \pm 21.9$ & $83.9 \pm 22.4$ & 0.325 \\
LVESVI $\left(\mathrm{mL} \mathrm{m}^{-2}\right)$ & $38.6 \pm 16.5$ & $36.0 \pm 14.9$ & 0.045 \\
IVSTd $(\mathrm{mm})$ & $12.3 \pm 3.6$ & $12.0 \pm 3.3$ & 0.262 \\
LVIDd $(\mathrm{mm})$ & $56.7 \pm 6.4$ & $56.6 \pm 6.4$ & 0.939 \\
LV mass/BSA $\left(\mathrm{g} \mathrm{m}^{-2}\right)$ & $57.7 \pm 16.3$ & $54.4 \pm 15.4$ & $<0.001$ \\
LA size $\left(\mathrm{cm}^{2}\right)$ & $25.6 \pm 7.2$ & $25.2 \pm 6.4$ & 0.257 \\
Global circumferential strain $(\%)$ & $-20.7 \pm 7.3$ & $-21.2 \pm 7.1$ & 0.280 \\
LVEF $(\%)$ & $55.4 \pm 11.0$ & $57.5 \pm 9.3$ & 0.057 \\
Hemodynamics $(n=58$ patients) & & & $<0.001$ \\
Systolic BP $(\mathrm{mmHg})$ & $172.8 \pm 23.6$ & $151.4 \pm 24.2$ & $<0.001$ \\
Diastolic BP $(\mathrm{mmHg})$ & $92.3 \pm 16.1$ & $84.6 \pm 16.5$ & $<0.001$ \\
Pulse pressure $(\mathrm{mmHg})$ & $80.5 \pm 15.0$ & $66.9 \pm 16.6$ & \\
Cross-sectional areas descending aorta $\left(\mathrm{mm}^{2}\right)(n=58$ patients $)$ & & 0.011 \\
Maximum area $(\mathrm{ES})$ & $604.7 \pm 157.7$ & $621.1 \pm 157.3$ & 0.110 \\
Minimal area (ED) & $541.5 \pm 138.5$ & $553.6 \pm 155.2$ & 0.153 \\
Aortic area change absolute & $63.2 \pm 34.3$ & $67.5 \pm 25.4$ & 0.262 \\
Aortic area change \% (aortic strain) & $11.7 \pm 5.6$ & $12.8 \pm 5.5$ & $<0.001$ \\
Descending aortic distensibility $\left(10^{-3} \mathrm{mmHg}^{-1}\right)$ & $1.52 \pm 0.82$ & $2.02 \pm 0.93$ & \\
& $1.47(0.90)^{\#}$ & $1.77(1.02)^{\#}$ & \\
\hline
\end{tabular}

Data are expressed as mean and standard deviation

LVEDVI left ventricular end-diastolic volume index, LVESVI left ventricular end-systolic volume index, IVSTd interventricular septal thickness at diastole, LVIDd left ventricular internal diameter at diastole, BSA body surface area, $L V$ left ventricle, $L A$ left atrium, $E F$ ejection fraction, $B P$ blood pressure, $E S$ end-systolic, $E D$ end-diastolic

${ }^{\#}$ For $\mathrm{AD}$, values are also given as median (interquartile range). All $p$ values are from the Wilcoxon test

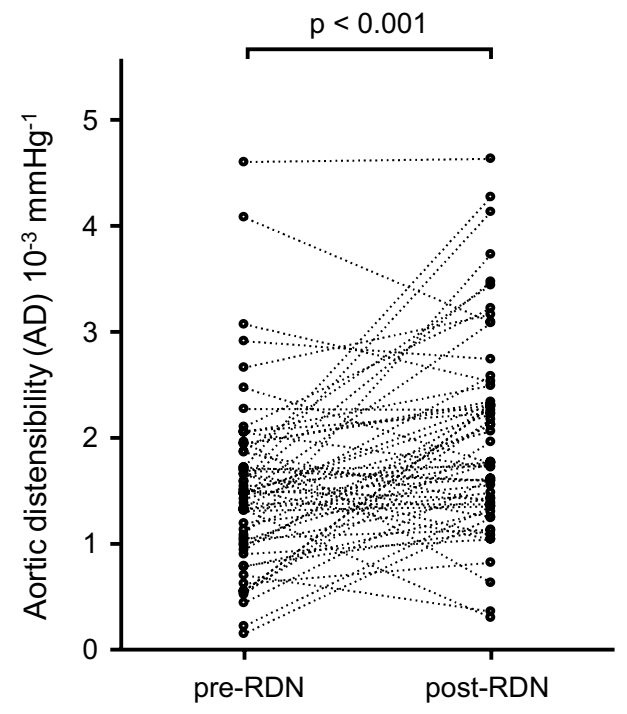

Fig. 1 Distribution of aortic distensibility (AD) at baseline and 6-month follow-up. AD had increased by 33\% post RDN at 6-month follow-up

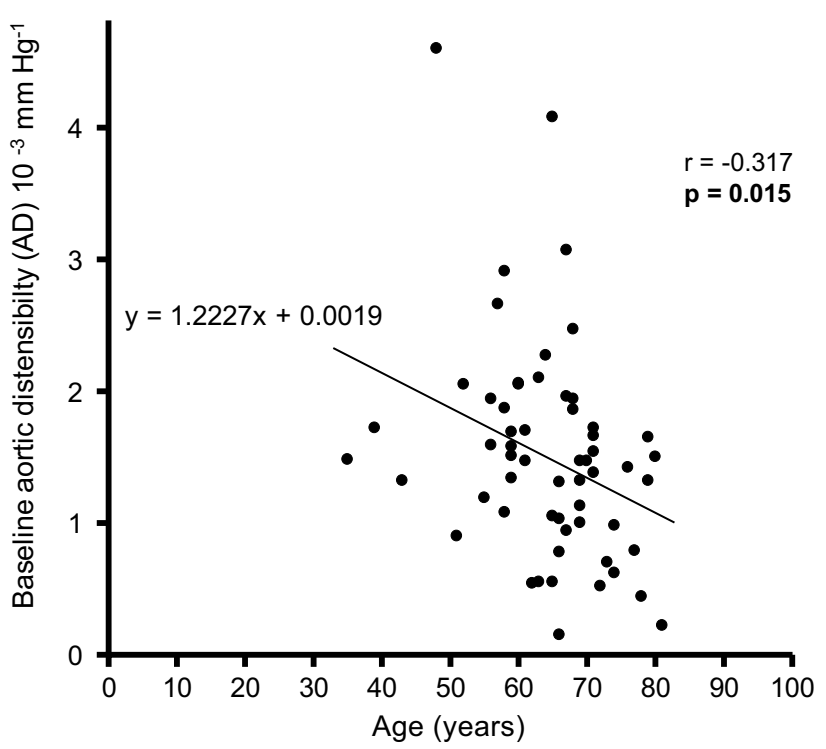

Fig. 2 Correlations of baseline aortic distensibility (AD) and patients age 


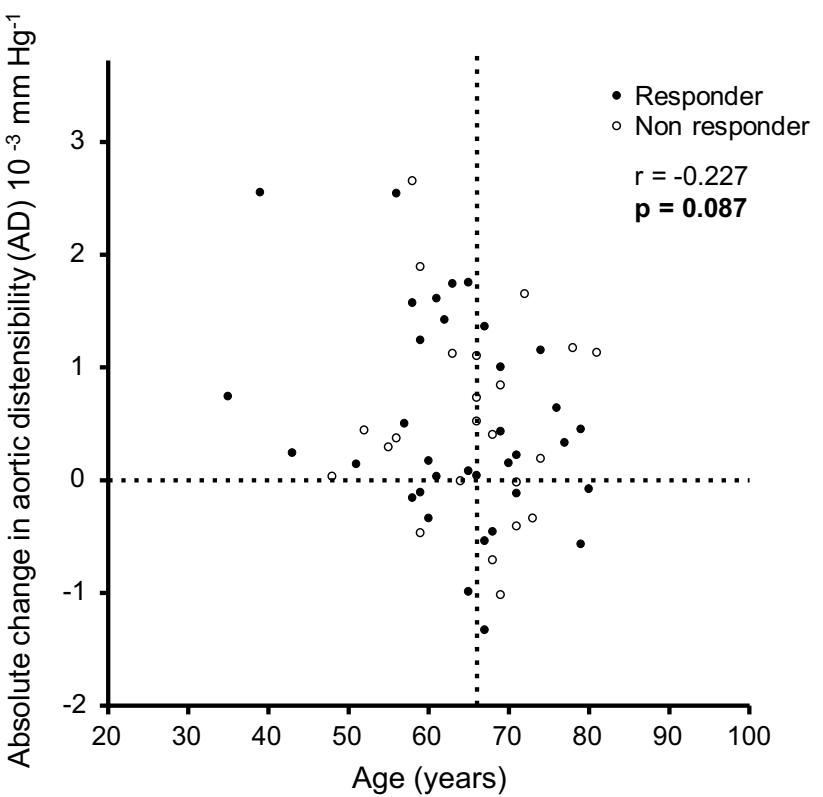

Fig. 3 Correlations of absolute change in aortic distensibility (AD) at 6-month follow-up and patients age. Response to RDN was defined as $\mathrm{a} \geq 10 \mathrm{mmHg}$ decrease in SBP

AD patients $(61.4 \pm 10.1$ vs. $67.1 \pm 8.4$ years, $p=0.022)$. No difference was observed in the other baseline clinical parameters. Office systolic and diastolic BP decreased significantly from $168 / 93 \pm 22 / 15 \mathrm{mmHg}$ at baseline to $149 / 86 \pm 22 / 17 \mathrm{mmHg}(p<0.001) 6$ months after RDN in the high $\mathrm{AD}$ group and from $177 / 92 \pm 25 / 17 \mathrm{mmHg}$ at baseline to $153 / 83 \pm 26 / 16 \mathrm{mmHg}(p<0.001)$ in the lowbaseline AD group; the difference in change between the groups was $6 / 2 \mathrm{mmHg}$.

\section{Discussion}

The analysis of the present multi-center study focused on the evaluation of $\mathrm{AD}$ in patients with RH undergoing RDN. Major findings were the following: (1) AD can be easily derived from 4-chamber cine views with high reproducibility. No additional CMR sequences are needed to obtain comprehensive information about the central vasculature through AD. (2) RDN significantly improved AD in patients with $\mathrm{RH}$, regardless of the BP response to the intervention. (3) There was evidence of age-independent improvements in $\mathrm{AD}$ after RDN.

Catheter-based RDN has been shown to reduce BP and sympathetic activity by modulation of renal sympathetic nerve fibers in animals and also humans [19, 21, 33]. Several clinical studies observed reductions in BP following RDN in patients with RH, but the results of the sham controlled Symplicity HTN-3 trial questioned the utility of RDN to lower BP [10, 26]. Various factors might explain the considerable heterogeneity in the effects of RDN on BP. Newer studies aim to avoid the confounding effects of BP lowering drugs and the variation in adherence to medical treatment [27]. At this point, the results of the proof-ofconcept trial SPYRAL HTN-OFF MED suggest efficacy of RDN on BP in the absence of antihypertensive medications $[13,28]$. Modulation of the sympathetic nervous system by RDN has been associated with reductions in left ventricular mass, improvements in obstructive sleep apnea severity, and occurrence of arrhythmias [3, 29-32]. A pilot study also demonstrated improved compliance measured by PWV after RDN, suggesting that these parameters better reflect the risk of later cardiac events than the reduction in SBP [33]. Augmentation index has also been shown to be beneficially affected by RDN [34]. Some of these pleiotropic effects may

Table 3 Aortic distensibility for the entire cohort by tertile of age at baseline

\begin{tabular}{|c|c|c|c|c|}
\hline Parameter & $\begin{array}{l}1 \text { st age tertile } \\
35-60 \text { years }(n=19)\end{array}$ & $\begin{array}{l}\text { 2nd age tertile } \\
61-68 \text { years }(n=19)\end{array}$ & $\begin{array}{l}\text { 3rd age tertile } \\
69-81 \text { years }(n=20)\end{array}$ & $p$ value \\
\hline \multicolumn{5}{|l|}{ Pulse pressure (mmHg) } \\
\hline Baseline & $78.4 \pm 14.7$ & $78.9 \pm 16.8$ & $81.3 \pm 15.6$ & 0.826 \\
\hline 6-month follow-up & $59.8 \pm 14.2$ & $68.1 \pm 11.9$ & $67.4 \pm 17.6$ & 0.166 \\
\hline \multicolumn{5}{|c|}{ Descending aortic distensibility $\left(10^{-3} \mathrm{mmHg}^{-1}\right)$} \\
\hline Baseline & $1.87 \pm 0.82$ & $1.57 \pm 0.98$ & $1.14 \pm 0.45$ & 0.019 \\
\hline 6-month follow-up & $2.62 \pm 1.10$ & $1.98 \pm 0.72$ & $1.48 \pm 0.56$ & $<0.001$ \\
\hline Absolute change at 6-month follow-up & $0.75 \pm 1.01$ & $0.41 \pm 0.96$ & $0.34 \pm 0.68$ & $0.318 / 0.008^{*}$ \\
\hline Relative change at 6-month follow-up & $40 \pm 54 \%$ & $26 \pm 61 \%$ & $29 \pm 30 \%$ & $0.459 / 0.434 * *$ \\
\hline
\end{tabular}

$p$ values by ANOVA

*Univariable Bonferroni correction using baseline distensibility as covariable

**1st vs. 2nd and 1st vs. 3rd tertile 


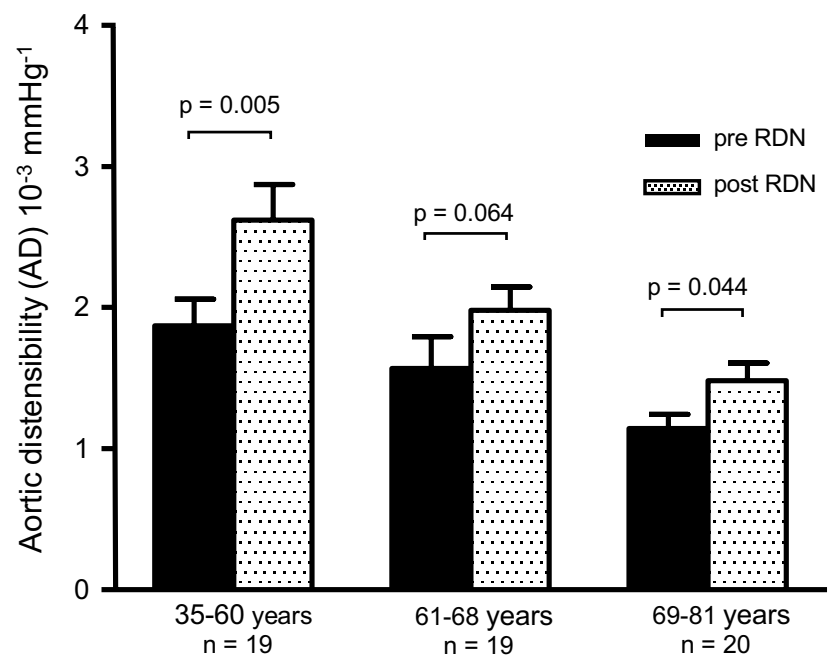

Fig. 4 Changes in aortic distensibility (AD) from baseline to 6-month follow-up regarding age group at baseline

be explained by the increased sodium excretion which has been reported after RDN [35].

Here, we used CMR-based AD to assess the effect of RDN on aortic compliance. RDN demonstrated a beneficial impact on vascular stiffness 6 month post-procedure. This effect was independent of the BP lowering efficacy of the procedure and more pronounced the lower the compliance was at baseline. Almost half of our patients (48\%) had isolated systolic hypertension, which mainly reflects the high rigidity and the decreased elasticity of the large vessels in this cohort. However, significant improvements in $\mathrm{AD}$ after RDN could be observed regardless of the type of hypertension.

During the natural course of arterial aging, structural and mechanical changes of the vascular wall lead to loss in elasticity and reduced vascular compliance [36]. An inverse relation of $\mathrm{AD}$ with age has been shown in several studies and most of the lifetime reduction in AD occurs before the age of $50[4,5,37]$. It is important to mention that the mean age herein was $64.4 \pm 9.6$ years, suggestive of a small range in $\mathrm{AD}$ improvement only. The observed changes in $\mathrm{AD}$ were indeed age dependent, but present among all age groups. This finding is congruent with the previous studies proving that the age-related decrease in systemic arterial stiffness is partially reversible [38]. Several authors have shown that the distal parts of the aorta seem to age slower than the more proximal ones [5, 39]. The performed measurements of $\mathrm{AD}$ in the descending aorta are hence appropriate to reflect vascular age in an elderly cohort.

The Multi-ethnic Study on Artherosclerosis (MESA) provided values of distensibility among 1160 healthy participants with a mean age of $60 \pm 9$ years [7]. Interestingly, the reported median descending AD in MESA of $1.75 \times 10^{-3} \mathrm{mmHg}^{-1}$ corresponds well with the median descending AD that our

Table 4 Cross-sectional aortic area measurements and aortic distensibility: comparison of baseline and follow-up parameters in patients with and without response to renal sympathetic denervation

\begin{tabular}{|c|c|c|c|c|c|c|c|c|}
\hline \multirow[t]{2}{*}{ Parameter } & \multicolumn{3}{|c|}{ Responders $(n=37)$} & \multicolumn{3}{|c|}{ Non-responders $(n=21)$} & \multirow{2}{*}{$\begin{array}{l}p \text { value } \\
\text { Baseline } \\
\text { Responder vs. non }\end{array}$} & \multirow{2}{*}{$\begin{array}{l}p \text { value } \\
\text { Follow-up } \\
\text { Responder vs. non }\end{array}$} \\
\hline & Baseline & Follow-up & $p$ value & Baseline & Follow-up & $p$ value & & \\
\hline \multicolumn{9}{|c|}{ Cross-sectional area descending aorta $\left(\mathrm{mm}^{2}\right)$} \\
\hline Maximum area & $580.0 \pm 130.7$ & $590.3 \pm 117.7$ & 0.294 & $648.2 \pm 192.6$ & $675.4 \pm 201.7$ & 0.005 & 0.216 & $0.137^{*}$ \\
\hline Minimal area & $516.6 \pm 109.5$ & $525.7 \pm 109.5$ & 0.346 & $585.4 \pm 173.0$ & $602.8 \pm 207.6$ & 0.140 & 0.143 & $0.541^{*}$ \\
\hline Aortic area change & $63.4 \pm 36.4$ & $64.5 \pm 22.7$ & 0.582 & $62.9 \pm 30.9$ & $72.6 \pm 29.4$ & 0.122 & 0.680 & $0.258^{*}$ \\
\hline $\begin{array}{l}\text { Aortic area change } \% \\
\text { (aortic strain) }\end{array}$ & $12.2 \pm 6.0$ & $12.6 \pm 4.9$ & 0.746 & $10.8 \pm 4.9$ & $13.2 \pm 6.5$ & 0.144 & 0.668 & $0.336^{*}$ \\
\hline Area change absolute & $1.1 \pm 29.0$ & & & $9.7 \pm 34.4$ & & & 0.336 & \\
\hline \multicolumn{9}{|c|}{ Distensibility descending aorta $\left(10^{-3} \mathrm{mmHg}^{-1}\right)$} \\
\hline Absolute values & $1.51 \pm 0.8$ & $2.0 \pm 0.84$ & 0.002 & $1.54 \pm 0.93$ & $1.98 \pm 1.11$ & 0.046 & 0.942 & $0.737^{*}$ \\
\hline $\begin{array}{l}\text { Distensibility change } \\
\text { absolute }\end{array}$ & $0.53 \pm 0.91$ & & & $0.44 \pm 0.89$ & & & $0.692\left(0.686^{* *}\right)$ & \\
\hline $\begin{array}{l}\text { Distensibility change } \\
\%\end{array}$ & $35.1 \pm 60.1$ & & & $28.6 \pm 58.0$ & & & 0.6901 & \\
\hline \multicolumn{9}{|l|}{ Pulse pressure $(\mathrm{mmHg})$} \\
\hline Absolute values & $82.9 \pm 14.2$ & $63.7 \pm 12.1$ & $<0.001$ & $73.8 \pm 16.2$ & $67.6 \pm 19.2$ & 0.265 & 0.031 & 0.346 \\
\hline
\end{tabular}

Response defined as systolic blood-pressure reduction at 6-month follow-up $\geq 10 \mathrm{mmHg}$. Data are expressed as mean and standard deviation *BL adjusted univariable analyses with Bonferroni estimates

**Age and baseline distensibility as covariables 


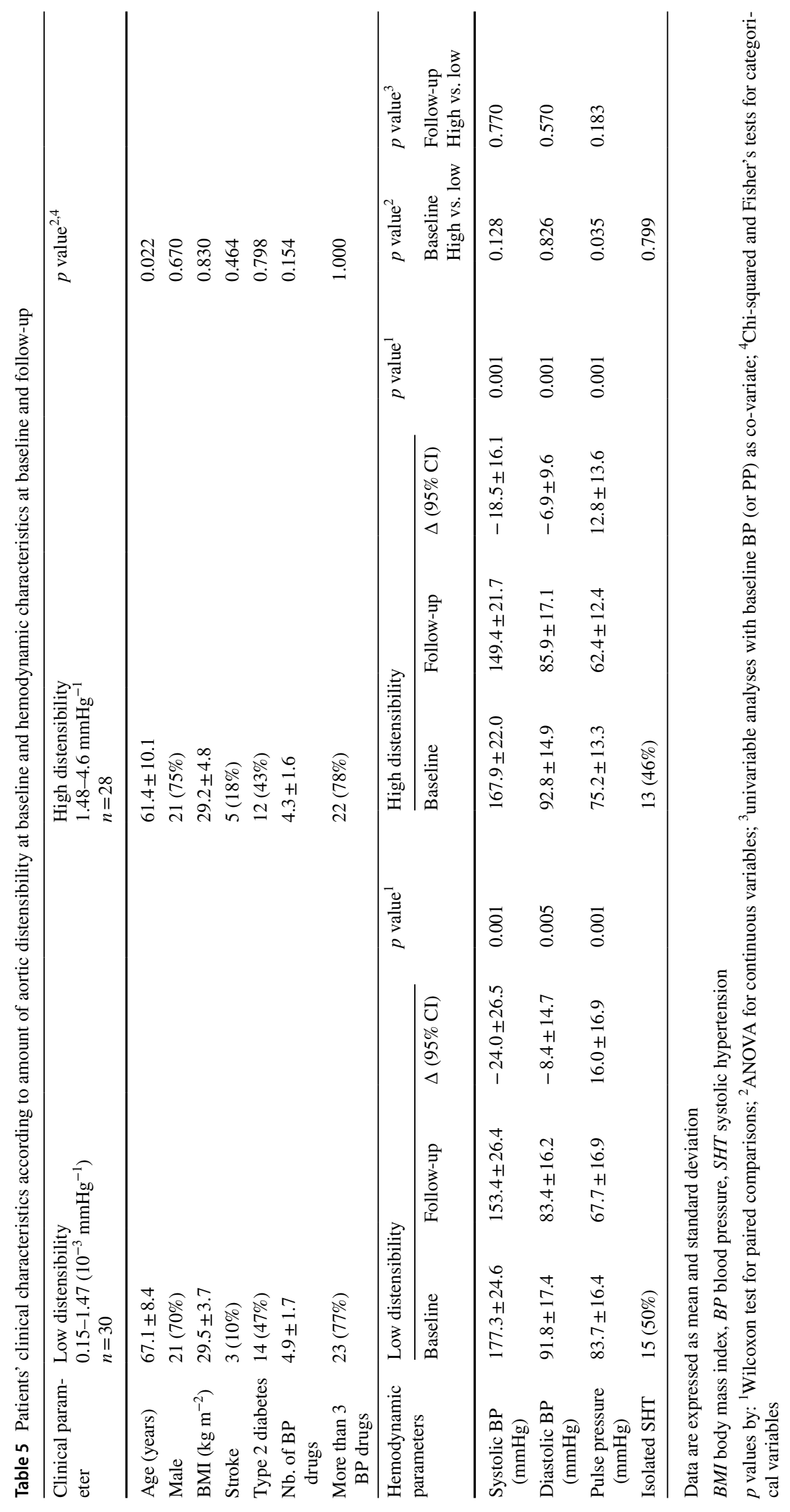




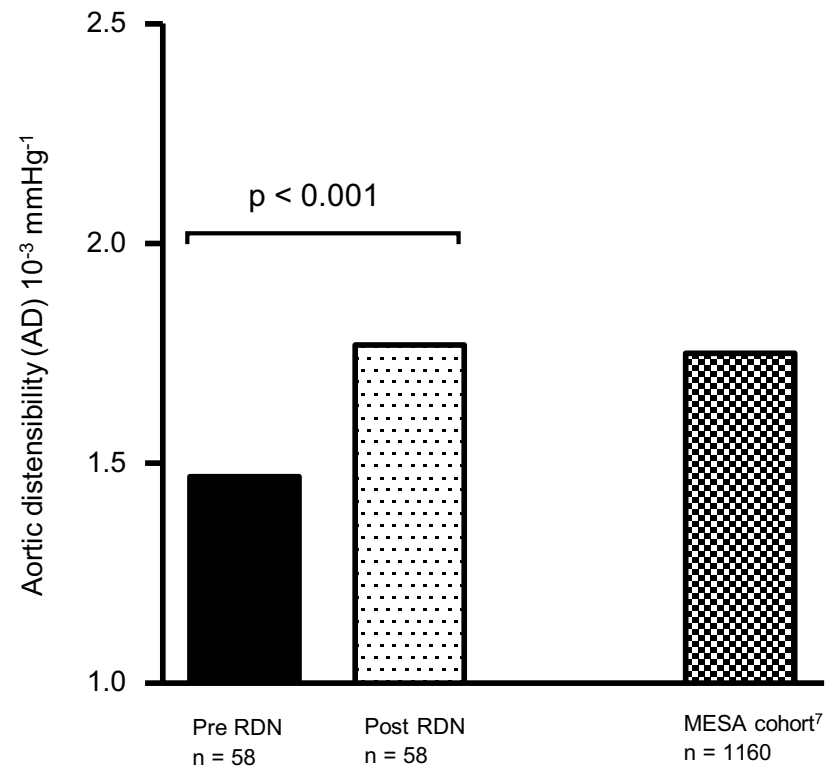

Fig. 5 Evolution in median aortic distensibility (AD) from baseline to 6-month follow-up (left) in comparison with norm values reported in the MESA trial (right) [7]

patients presented 6 months after $\mathrm{RDN}\left(1.77 \times 10^{-3} \mathrm{mmHg}^{-1}\right)$ [7]. Figure 5 illustrates the evolution in our cohort from baseline to 6-month follow-up in comparison with the MESA collective. Hence, RDN improved the impaired $\mathrm{AD}$ in our cohort by about $30 \%$ and values appeared to return to levels obtained in an age-matched reference group 6 months after treatment. Importantly, our study supports the notion that renal denervation exerts clinically relevant effects beyond simple bloodpressure lowering, in this case pertaining to aortic vascular properties.

Longer term follow-up data will be important to better appreciate the apparent BP-independent effects of RDN and their impact on the cardiovascular risk profile of treated patients.

The identification of baseline predictors of response to RDN remains a central question of interest. We hypothesized that a reduction in SBP achieved by RDN was largest among patients with high $\mathrm{AD}$ and thus the lowest burden of aortic stiffness. However, this was not the case and response to RDN was independent of $\mathrm{AD}$ at baseline. Future trials will be needed to find out whether AD can ease the selection of patients with a likely response to RDN. Potentially, additional assessment of aortic wall calcification (evaluated by $\mathrm{CT}$ ) already existing at baseline in combination with the assessment of vascular compliance by CMR will further increase the prediction of response to RDN [40].

\section{Limitations}

The limitations of the Symplicity trials (NCT00664638, NCT00888433, and NCT01888315) have been discussed elsewhere [41]. The major limitations of our study include the non-randomized design and the fact that the study was not primarily designed to assess the effects of RDN on AD. Furthermore, the number of included patients was relatively small. However, we used CMR to explore effects on $\mathrm{AD}$ which represents a highly reproducible method compared to echocardiography, resulting in a considerable reduction in sample sizes of up to $90 \%$. This has been underlined by the high ICC values of the present study despite the small cohort of patients. Measurements of PWV or any other marker of large vascular dysfunction reflecting vascular stiffness were not included in the study protocol, making a direct comparison of these parameters impossible. Office BP but not central BP was used to calculate AD. Central BP measured during MRI would have been very likely to provide more precise information on AD. The invasiveness though clearly limits the feasibility of these measurements; hence, we decided to rely on noninvasive brachial pressures. A limitation of this trial is the missing sham group. A placebo or Hawthorne effect can, therefore, not be fully excluded. Finally, the adherence to medication could not be confirmed by urine levels of antihypertensive drugs. Patients had specific instructions not to change antihypertensive therapy during the study period. Only one patient in our cohort reported to have increased his dose of diuretics. Medication changes may have effects on arterial stiffness in addition to RDN and may influence $\mathrm{AD}$.

\section{Conclusion}

Our results underline the direct neurohormonal influence of RDN on vascular tone and aortic stiffness and propose that CMR determined $\mathrm{AD}$ may be most suitable in the evaluation of aortic compliance in invasive BP therapy. Indeed, other parameters considered to integrate alterations of vascular compliance and arterial stiffness such as isolated systolic hypertension, augmentation index, and pulse wave velocity have been demonstrated to improve with RDN. By evaluating $\mathrm{AD}$ in the descending aorta, we present a simple, robust, and reproducible method to record changes in aortic stiffness. The present data illustrate that the effects of RDN are not limited by age and can improve compliance even in patients with a low-baseline compliance. A next step would be to include $\mathrm{AD}$ as part of an aortic routine analysis to further evaluate the prognostic value of this method. 
Acknowledgements We would like to thank all institutions for their collaboration in this project and our MR technicians for helping with the high quality CMR examinations. We also thank Anne Gale for editorial assistance.

\section{Compliance with ethical standards}

Conflict of interest All institutions received scientific support from Medtronic/Ardian. FM, MPS, MDE, and MB were investigators for the Simplicity HTN-1 and HTN-2 trial. FM, MPS, MDE, and MB have received speaker honoraria and consultancy fees from Medtronic/ Ardian, St. Jude, Boston Scientific, and/or Cordis. MB is supported by Deutsche Forschungsgemeinschaft (KFO 196). FM is supported by Deutsche Hochdruckliga. FM and MB are supported by Deutsche Gesellschaft für Kardiologie. TL received support from the Hospital of Lithuanian University of Health Sciences. SK was supported by Philips Healthcare. TL, SK, and BP received support from the DZHK (German Center for Cardiovascular Research), Partner Site Berlin. The German Heart Center Berlin is supported by Foundation German Heart Center Berlin.

Open Access This article is distributed under the terms of the Creative Commons Attribution 4.0 International License (http://creativeco mmons.org/licenses/by/4.0/), which permits unrestricted use, distribution, and reproduction in any medium, provided you give appropriate credit to the original author(s) and the source, provide a link to the Creative Commons license, and indicate if changes were made.

\section{References}

1. Fleenor BS, Berrones AJ (2015) Arterial stiffness: implications and interventions. Springer, Cham

2. Daugherty SL, Powers JD, Magid DJ, Tavel HM, Masoudi FA, Margolis KL, O'Connor PJ, Selby JV, Ho PM (2012) Incidence and prognosis of resistant hypertension in hypertensive patients. Circulation 125:1635-1642

3. Mahfoud F, Urban D, Teller D, Linz D, Stawowy P, Hassel JH, Fries P, Dreysse S, Wellnhofer E, Schneider G, Buecker A, Schneeweis C, Doltra A, Schlaich MP, Esler MD, Fleck E, Bohm M, Kelle S (2014) Effect of renal denervation on left ventricular mass and function in patients with resistant hypertension: data from a multi-centre cardiovascular magnetic resonance imaging trial. Eur Heart J 35:2224-2231

4. Rose JL, Lalande A, Bouchot O, Bourennane el B, Walker PM, Ugolini P, Revol-Muller C, Cartier R, Brunotte F (2010) Influence of age and sex on aortic distensibility assessed by mri in healthy subjects. Magn Reson Imaging 28:255-263

5. Redheuil A, Yu WC, Wu CO, Mousseaux E, de Cesare A, Yan R, Kachenoura N, Bluemke D, Lima JA (2010) Reduced ascending aortic strain and distensibility: earliest manifestations of vascular aging in humans. Hypertension 55:319-326

6. Noda C, Ambale Venkatesh B, Ohyama Y, Liu CY, Chamera E, Redheuil A, Teixido-Tura G, Chugh AR, Wu CO, Hundley GW, Bluemke DA, Lima JA (2016) Reproducibility of functional aortic analysis using magnetic resonance imaging: the mesa. Eur Heart J Cardiovasc Imaging 17:909-917

7. Ohyama Y, Teixido-Tura G, Ambale-Venkatesh B, Noda C, Chugh AR, Liu CY, Redheuil A, Stacey RB, Dietz H, Gomes AS, Prince MR, Evangelista A, Wu CO, Hundley WG, Bluemke DA, Lima JA (2016) Ten-year longitudinal change in aortic stiffness assessed by cardiac mri in the second half of the human lifespan: the multi-ethnic study of atherosclerosis. Eur Heart J Cardiovasc Imaging 17:1044-1053

8. Perlini S, Palladini G, Ferrero I, Tozzi R, Fallarini S, Facoetti A, Nano R, Clari F, Busca G, Fogari R, Ferrari AU (2005) Sympathectomy or doxazosin, but not propranolol, blunt myocardial interstitial fibrosis in pressure-overload hypertrophy. Hypertension 46:1213-1218

9. DiBona GF (2005) Physiology in perspective: the wisdom of the body. Neural control of the kidney. Am J Physiol Regul Integr Comp Physiol 289:R633-641

10. Bhatt DL, Kandzari DE, O'Neill WW, D'Agostino R, Flack JM, Katzen BT, Leon MB, Liu M, Mauri L, Negoita M, Cohen SA, Oparil S, Rocha-Singh K, Townsend RR, Bakris GL (2014) A controlled trial of renal denervation for resistant hypertension. N Engl J Med 370:1393-1401

11. Esler MD, Krum H, Sobotka PA, Schlaich MP, Schmieder RE, Bohm M (2010) Renal sympathetic denervation in patients with treatment-resistant hypertension (the symplicity htn-2 trial): a randomised controlled trial. Lancet 376:1903-1909

12. Krum H, Schlaich M, Whitbourn R, Sobotka PA, Sadowski J, Bartus K, Kapelak B, Walton A, Sievert H, Thambar S, Abraham WT, Esler M (2009) Catheter-based renal sympathetic denervation for resistant hypertension: a multicentre safety and proof-of-principle cohort study. Lancet 373:1275-1281

13. Townsend RR, Mahfoud F, Kandzari DE, Kario K, Pocock S, Weber MA, Ewen S, Tsioufis K, Tousoulis D, Sharp ASP, Watkinson AF, Schmieder RE, Schmid A, Choi JW, East C, Walton A, Hopper I, Cohen DL, Wilensky R, Lee DP, Ma A, Devireddy CM, Lea JP, Lurz PC, Fengler K, Davies J, Chapman N, Cohen SA, DeBruin V, Fahy M, Jones DE, Rothman M, Bohm M (2017) Catheter-based renal denervation in patients with uncontrolled hypertension in the absence of antihypertensive medications (SPYRAL HTN-OFF MED): a randomised, sham-controlled, proof-of-concept trial. Lancet 390(10108):2160-2170

14. Mancia G, Fagard R, Narkiewicz K, Redon J, Zanchetti A, Böhm M, Christiaens T, Cifkova R, De Backer G, Dominiczak A, Galderisi M, Grobbee DE, Jaarsma T, Kirchhof P, Kjeldsen SE, Laurent S, Manolis AJ, Nilsson PM, Ruilope LM, Schmieder RE, Sirnes PA, Sleight P, Viigimaa M, Waeber B, Zannad F, Burnier M, Ambrosioni E, Caufield M, Coca A, Olsen MH, Tsioufis C, van de Borne P, Zamorano JL, Achenbach S, Baumgartner H, Bax JJ, Bueno H, Dean V, Deaton C, Erol C, Ferrari R, Hasdai D, Hoes AW, Knuuti J, Kolh P, Lancellotti P, Linhart A, Nihoyannopoulos P, Piepoli MF, Ponikowski P, Tamargo JL, Tendera M, Torbicki A, Wijns W, Windecker S, Clement DL, Gillebert TC, Rosei EA, Anker SD, Bauersachs J, Hitij JB, Caulfield M, De Buyzere M, De Geest S, Derumeaux GA, Erdine S, Farsang C, Funck-Brentano C, Gerc V, Germano G, Gielen S, Haller H, Jordan J, Kahan T, Komajda M, Lovic D, Mahrholdt H, Ostergren J, Parati G, Perk J, Polonia J, Popescu BA, Reiner Z, Ryden L, Sirenko Y, Stanton A, Struijker-Boudier H, Vlachopoulos C, Volpe M, Wood DA (2013) 2013 esh/esc guidelines for the management of arterial hypertension: the task force for the management of arterial hypertension of the european society of hypertension (esh) and of the european society of cardiology (esc). Eur Heart J 34:2159-2219

15. Mahfoud F, Luscher TF, Andersson B, Baumgartner I, Cifkova R, Dimario C, Doevendans P, Fagard R, Fajadet J, Komajda M, Lefevre T, Lotan C, Sievert H, Volpe M, Widimsky P, Wijns W, Williams B, Windecker S, Witkowski A, Zeller T, Bohm M (2013) Expert consensus document from the european society of cardiology on catheter-based renal denervation. Eur Heart J 34:2149-2157

16. Mahfoud F, Ukena C, Schmieder RE, Cremers B, Rump LC, Vonend O, Weil J, Schmidt M, Hoppe UC, Zeller T, Bauer A, Ott C, Blessing E, Sobotka PA, Krum H, Schlaich M, Esler M, 
Bohm M (2013) Ambulatory blood pressure changes after renal sympathetic denervation in patients with resistant hypertension. Circulation 128:132-140

17. Kelle S, Roes SD, Klein C, Kokocinski T, de Roos A, Fleck E, Bax JJ, Nagel E (2009) Prognostic value of myocardial infarct size and contractile reserve using magnetic resonance imaging. J Am Coll Cardiol 54:1770-1777

18. Schulz-Menger J, Bluemke DA, Bremerich J, Flamm SD, Fogel MA, Friedrich MG, Kim RJ, von Knobelsdorff-Brenkenhoff F, Kramer CM, Pennell DJ, Plein S, Nagel E (2013) Standardized image interpretation and post processing in cardiovascular magnetic resonance: Society for Cardiovascular Magnetic Resonance (SCMR) board of trustees task force on standardized post processing. J Cardiovasc Magn Reson 15:35

19. Vogel-Claussen J, Finn JP, Gomes AS, Hundley GW, JeroschHerold M, Pearson G, Sinha S, Lima JA, Bluemke DA (2006) Left ventricular papillary muscle mass: relationship to left ventricular mass and volumes by magnetic resonance imaging. J Comput Assist Tomogr 30:426-432

20. Papavassiliu T, Kuhl HP, van Dockum W, Hofman MB, Bondarenko O, Beek IA, van Rossum AC (2004) Accuracy of one- and two-dimensional algorithms with optimal image plane position for the estimation of left ventricular mass: a comparative study using magnetic resonance imaging. J Cardiovasc Magn Reson 6:845-854

21. Puntmann VO, Gebker R, Duckett S, Mirelis J, Schnackenburg B, Graefe M, Razavi R, Fleck E, Nagel E (2013) Left ventricular chamber dimensions and wall thickness by cardiovascular magnetic resonance: comparison with transthoracic echocardiography. Eur Heart J Cardiovasc Imaging 14:240-246

22. Doltra A, Hartmann A, Stawowy P, Goubergrits L, Kuehne T, Wellnhofer E, Gebker R, Schneeweis C, Schnackenburg B, Esler M, Fleck E, Kelle S (2016) Effects of renal denervation on renal artery function in humans: preliminary study. PLoS One 11:e0150662

23. Azizi M, Sapoval M, Gosse P, Monge M, Bobrie G, Delsart P, Midulla M, Mounier-Vehier C, Courand PY, Lantelme P, Denolle T, Dourmap-Collas C, Trillaud H, Pereira H, Plouin PF, Chatellier G (2015) Optimum and stepped care standardised antihypertensive treatment with or without renal denervation for resistant hypertension (denerhtn): a multicentre, open-label, randomised controlled trial. Lancet 385:1957-1965

24. Oppo K, Leen E, Angerson WJ, Cooke TG, McArdle CS (1998) Doppler perfusion index: an interobserver and intraobserver reproducibility study. Radiology 208:453-457

25. Ukena C, Cremers B, Ewen S, Bohm M, Mahfoud F (2013) Response and non-response to renal denervation: who is the ideal candidate? EuroIntervention 9(Suppl R):R54-R57

26. Persu A, Jin Y, Azizi M, Baelen M, Volz S, Elvan A, Severino F, Rosa J, Adiyaman A, Fadl Elmula FE, Taylor A, Pechere-Bertschi A, Wuerzner G, Jokhaji F, Kahan T, Renkin J, Monge M, Widimsky P, Jacobs L, Burnier M, Mark PB, Kjeldsen SE, Andersson B, Sapoval M, Staessen JA (2014) Blood pressure changes after renal denervation at 10 european expert centers. J Hum Hypertens 28:150-156

27. Persu A, Kjeldsen S, Staessen JA, Azizi M (2016) Renal denervation for treatment of hypertension: a second start and new challenges. Curr Hypertens Rep 18:6
28. Kulenthiran S, Ewen S, Bohm M, Mahfoud F (2017) Hypertension up to date: sprint to spyral. Clin Res Cardiol 106:475-484

29. Kiuchi MG, GR ES, Paz LM, Chen S, Souto GL (2016) Proof of concept study: renal sympathetic denervation for treatment of polymorphic premature ventricular complexes. J Interv Card Electrophysiol 47:221-229

30. Shantha GP, Pancholy SB (2015) Effect of renal sympathetic denervation on apnea-hypopnea index in patients with obstructive sleep apnea: a systematic review and meta-analysis. Sleep Breath 19:29-34

31. Ukena C, Mahfoud F, Ewen S, Bollmann A, Hindricks G, Hoffmann BA, Linz D, Musat D, Pavlicek V, Scholz E, Thomas D, Willems S, Bohm M, Steinberg JS (2016) Renal denervation for treatment of ventricular arrhythmias: data from an international multicenter registry. Clin Res Cardiol 105:873-879

32. Donazzan L, Mahfoud F, Ewen S, Ukena C, Cremers B, Kirsch CM, Hellwig D, Eweiwi T, Ezziddin S, Esler M, Bohm M (2016) Effects of catheter-based renal denervation on cardiac sympathetic activity and innervation in patients with resistant hypertension. Clin Res Cardiol 105:364-371

33. Mortensen K, Franzen K, Himmel F, Bode F, Schunkert H, Weil J, Reppel M (2012) Catheter-based renal sympathetic denervation improves central hemodynamics and arterial stiffness: a pilot study. J Clin Hypertens (Greenwich) 14:861-870

34. Hering D, Lambert EA, Marusic P, Ika-Sari C, Walton AS, Krum H, Sobotka PA, Mahfoud F, Bohm M, Lambert GW, Esler MD, Schlaich MP (2013) Renal nerve ablation reduces augmentation index in patients with resistant hypertension. J Hypertens 31:1893-1900

35. Poss J, Ewen S, Schmieder RE, Muhler S, Vonend O, Ott C, Linz D, Geisel J, Rump LC, Schlaich M, Bohm M, Mahfoud F (2015) Effects of renal sympathetic denervation on urinary sodium excretion in patients with resistant hypertension. Clin Res Cardiol 104:672-678

36. Jani B, Rajkumar C (2006) Ageing and vascular ageing. Postgrad Med J 82:357-362

37. Rerkpattanapipat P, Hundley WG, Link KM, Brubaker PH, Hamilton CA, Darty SN, Morgan TM, Kitzman DW (2002) Relation of aortic distensibility determined by magnetic resonance imaging in patients $>$ or $=60$ years of age to systolic heart failure and exercise capacity. Am J Cardiol 90:1221-1225

38. Cameron JD, Dart AM (1994) Exercise training increases total systemic arterial compliance in humans. Am J Physiol 266:H693-701

39. Hickson SS, Butlin M, Graves M, Taviani V, Avolio AP, McEniery CM, Wilkinson IB (2010) The relationship of age with regional aortic stiffness and diameter. JACC Cardiovasc Imaging 3:1247-1255

40. Courand PY, Pereira H, Del Giudice C, Gosse P, Monge M, Bobrie G, Delsart P, Mounier-Vehier C, Lantelme P, Denolle T, Dourmap C, Halimi JM, Girerd X, Rossignol P, Zannad F, Ormezzano O, Vaisse B, Herpin D, Ribstein J, Bouhanick B, Mourad JJ, Ferrari E, Chatellier G, Sapoval M, Azarine A, Azizi M (2017) Abdominal aortic calcifications influences the systemic and renal hemodynamic response to renal denervation in the denerhtn (renal denervation for hypertension) trial. J Am Heart Assoc 6:e007062

41. Mahfoud F, Luscher TF (2015) Renal denervation: symply trapped by complexity? Eur Heart J 36:199-202 